Article

\title{
On Adaptive Control for Electrical Discharge Machining Using Vibroacoustic Emission
}

\author{
Yury A. Melnik@, Mikhail P. Kozochkin, Artur N. Porvatov and Anna A. Okunkova* \\ Department of High-efficiency Machining Technologies, Moscow State University of Technology STANKIN, \\ Vadkovskiy per.3A, 127055 Moscow, Russia; yu.melnik@stankin.ru (Y.A.M.); m.kozochkin@stankin.ru (M.P.K.); \\ vto@stankin.ru (A.N.P.) \\ * Correspondence: a.okunkova@stankin.ru; Tel.: +7-909-913-12-07
}

Received: 16 October 2018; Accepted: 23 October 2018; Published: 24 October 2018

\begin{abstract}
The article is related to the research of the parameters of vibroacoustic emission for development of the monitoring and adaptive control system for electrical discharge machining. The classical control system based on a response of electrical parameters does not give an adequate data in the cases of a new class of materials processing as conductive ceramics reinforced by conductive nano additives and carbon nanotubes and whiskers. The idle pulses, which are working on the destruction of the erosion products in the gap, count as working pulses. The application of the monitoring and control tools based on vibroacoustic emission gives adequate data about conditions in the working zone. The developed system is available to count only impulses involved in working on the destruction of the workpiece. The experiments were conducted on the samples of materials with a low melting point as austenitic steel and aluminum alloy, and hard alloys. The records of vibroacoustic signals were analyzed for detection of the monitoring and adaptive control criteria.
\end{abstract}

Keywords: electrical discharge machining; vibroacoustic emission; adaptive control; monitoring; discharge gap; erosion products

\section{Introduction}

Today it is impossible to imagine the production of high-accuracy parts with complex volumetric geometry and internal cooling system without electrical discharge machining (EDM) [1-3]. The application of the technology was significantly extended by adding from 1 to 3 independent rotating axes [4-6].

Hence, practice shows that up to now EDM has uncontrollable problems related to decreasing of productivity and quality of machined surfaces during conventional processing of easy-to-work materials [7-9]. Mainly it is critical in the case of machining of narrow slots array. E.g., $20 \div 24$ slots with the sizes in the plan $1.5 \times 8 \mathrm{~mm}$, and height of $15 \div 25 \mathrm{~mm}$ for production of the mold die with push-type ejectors for the part as a body of motor vehicle backlight [10]. In this case, a wire tool can be stuck between a workpiece and a cut-out industrial waste (or part), that leads to the undesirable issues related to process instability, short circuit, wire break, sometimes even to diamond nozzle damage [11-14].

Nowadays, the use of ceramic products in the industry is continuously growing due to its excellent exploitation properties $[15,16]$. Plenty of scientists aim their study on the development of a new class of materials as conductive ceramic nanocomposites [17-19]. This kind of material should provide mechanical properties up to the level of continent ceramics or even exceed them, but also be suitable for electrical discharge machining. By other words, it should be conductive [20]. The conductivity should be assured by conductive nano-sized additives as $\mathrm{TiC}, \mathrm{ZrC}, \mathrm{Nb}_{(2)} \mathrm{C}$ [21-23], when $\mathrm{SiCw}$ or carbon in the form of nanotubes or whiskers are responsible for supporting and improving 
mechanical properties [24,25]. It makes the questions related to ensuring of the uninterrupted electrical discharge machining using in-situ monitoring critical and significant to adapt the electrical parameters of machining and to prevent all undesirable effects during processing.

The tools of diagnostics based on vibroacoustic emission are known for application to the conventional mechanical machining for providing better reliability of the machine tools $[26,27]$. The vibroacoustic diagnostic tools aim to detect the moment of beating between a tool and a workpiece [28-30]. It allows controlling the operating element movements, preventing accidents. It was proved that based on the vibroacoustic signal it is possible to develop a new class of multiparametric diagnostic and adaptive control system [31]. The significant advantage of vibroacoustic diagnostics is the simplicity of the accelerometers' installation on the elastic system of the machine.

The scientific novelty of the article is in development and application diagnostic system based on vibroacoustic emission to the electrical discharge machining methods, which are known by an impossibility for the visual monitoring tools. The tasks of the current study are:

(1) Research a fundamental possibility of vibroacoustic diagnostics of wire electrical discharge machining;

(2) Adapt the existed method of in-situ vibroacoustic monitoring for EDM, make the comparison of the receive spectra of the signal with the electrical parameters of the machine;

(3) Analyze the obtained spectra and make understandable the criteria of deciding for development of the adaptive control system based on vibroacoustic emission;

(4) Demonstrate an opportunity of the in-situ adaptive control of EDM by specific examples of the machining.

\section{Materials and Methods}

The experiments were carried out at an industrial 4-axis EDM machine with CNC-controller Seibu M500S (Seibu, Fukuoka, Japan). A 0.25 mm-diameter brass wire of CuZn35 was used as a tool. Deionized water was used as a dielectric medium. Electrical discharge machining was produced with the immersion of the workpiece.

The accelerometers (Figure 1) of the developed vibroacoustic monitoring systems were installed at the upper guide (5) of the machine and on the system of the fastening of the workpiece (3). It was found that during electrical discharge machining the upper accelerometer (7) gave a more informative and symmetric signal than the accelerometer from the lower guide (8). It can be explain by presence of the disturbance influence from the working dielectric pump and driving gears of the machine. Further, only the signal from the upper guide was taken into account.

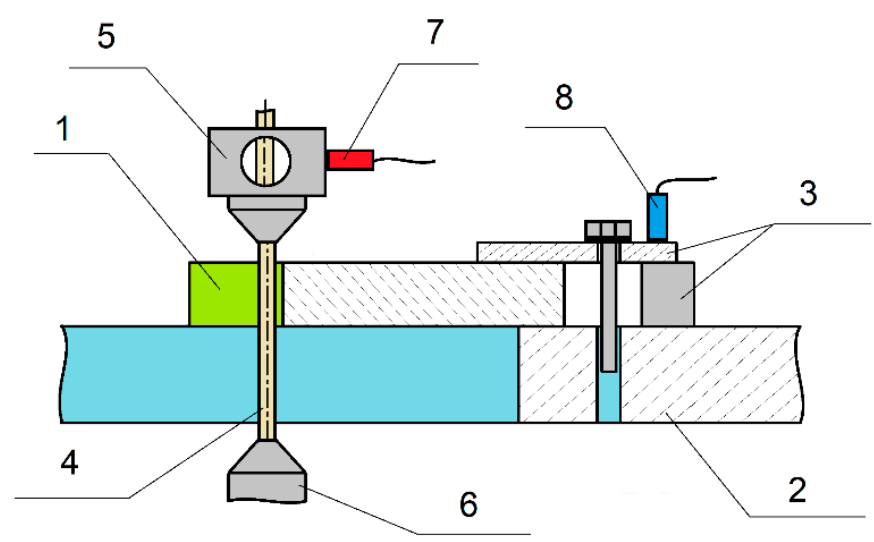

Figure 1. The positions of accelerometers in the working area of EDM machine, where (1) is a workpiece, (2) is a worktable, (3) is a fastening system, (4) is a wire electrode, (5) is an upper guide, (6) is a lower guide, (7) is an upper accelerometer, (8) is a lower accelerometer. 
A $200 \times 20 \times 16$ mm-blank of austenitic stainless steel AISI 321 [32,33] and a $200 \times 16 \times 16 \mathrm{~mm}$-blank of aluminum alloy AISI 2024 [34-36] samples (Table 1) were used at the first stage of the experiments for developing of the system of diagnostics and monitoring based on vibroacoustic emission for the needs of electrical discharge machining. The blanks were fastened on the worktable of EDM machine tool.

Table 1. The chemical composition of AISI 321 steel and AISI 2024 alloy, \%.

\begin{tabular}{|c|c|c|c|c|c|c|c|c|c|c|c|c|}
\hline Material & $\mathrm{Fe}$ & $\mathrm{Cr}$ & $\mathrm{C}$ & $\mathrm{Ni}$ & Mn & $\mathrm{Ti}$ & $\mathbf{P}$ & $\mathrm{Cu}$ & $\mathrm{Si}$ & $\mathrm{Zn}$ & $\mathrm{Mg}$ & Al \\
\hline $\begin{array}{c}\text { AISI } \\
321\end{array}$ & $44.9-59.1$ & $17-19$ & $\sim 12$ & $9-11$ & $\sim 2$ & $\sim 0.8$ & $\sim 0.035$ & $\sim 0.03$ & $\sim 0.02$ & - & - & - \\
\hline $\begin{array}{l}\text { AISI } \\
2024\end{array}$ & $\sim 0.5$ & - & - & $\sim 0.1$ & $0.3-0.9$ & $\sim 0.1$ & - & $3.8-4.9$ & $\sim 0.5$ & $\sim 0.3$ & $1.2-1.8$ & $90.8-94.7$ \\
\hline
\end{tabular}

The processing was done with the immersion of the blanks in a dielectric for $10 \mathrm{~min}$ before machining; it was done according to the EDM standards for high precision processing to exclude the thermal shrinkage of the materials [37]. The level of the dielectric was 1-2 $\mathrm{mm}$ above the blanks. The nozzle of the upper guide was installed as close as possible to the level of dielectric [38].

2- and $10 \mathrm{~mm}$-width samples were cut off from the blanks. During the processing, offset of the pass on the value of the discharge gap and the radius of the wire was ignored. The EDM parameters of processing were calculated following the standard machine tool recommendations for the proposed materials. The parameter of wire tension and voltage were varied during processing in the range of \pm 5 machine measurement units from the recommended values of the mentioned parameters.

The developed system of diagnostic and monitoring was approbated on EDM machine CUT1000 (GF AgieCharmilles SA, Losone, Switzerland). For this purpose, $100 \times 12 \times 12 \mathrm{~mm}$-blanks of hard alloys M05 [39,40] and P10 [41,42] by ISO (Table 2) were processed according to the prepared manually CNC-program. The standard EDM parameters for SKD-61 alloy [43] were chosen for machining. The frequencies of pulses changed during processing to create conditions for instability and provocation of a series of short circuits and wire breaks.

Table 2. The chemical composition of M05 and P10 hard alloys, \%.

\begin{tabular}{ccccc}
\hline Material & WC & TaC & TiC & Co \\
\hline M05 & 92 & 2 & - & 6 \\
P10 & 79 & - & 15 & 6 \\
\hline
\end{tabular}

The developed in-situ monitoring system based on vibroacoustic emission for electrical discharge machining is presented in Figure 2. The signals received from the accelerometers depend on the nature and intensity of the vibrations during processing, which depends on the parameters of electrical discharge machining. The signals were directed to an ADC and recorded. It was decided to take attention on the signal at the moment wire tool penetration into the blank, and at the end of processing: on 1st minute, 30th and 5th seconds before the end of CNC-program. Spectral analysis was performed in the range of frequencies from 1 to $32 \mathrm{kHz}$. 


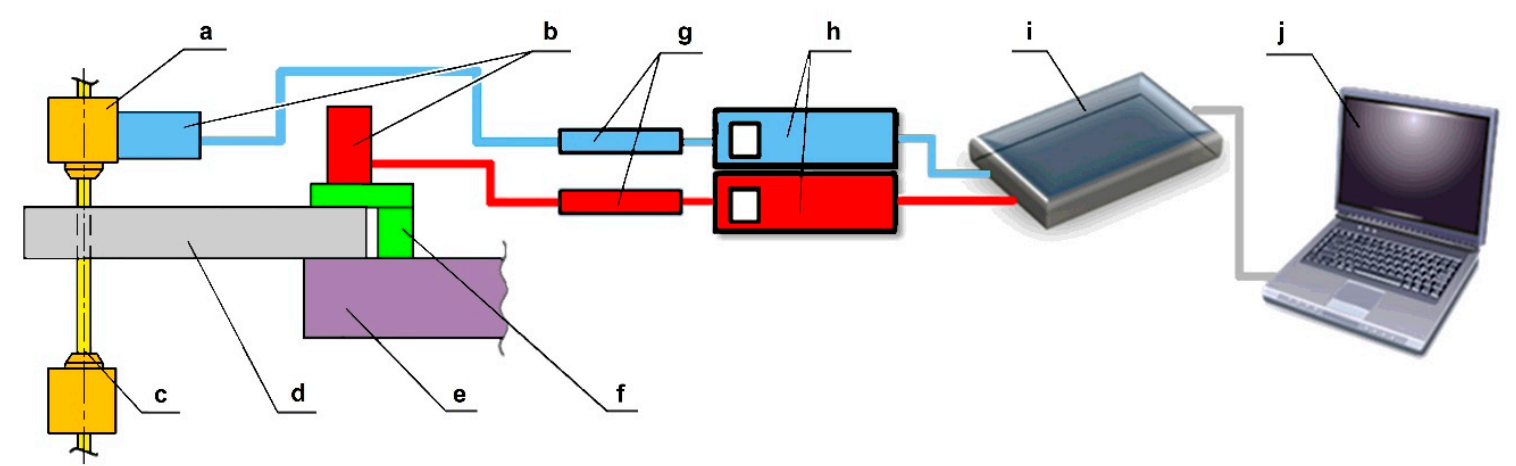

Figure 2. Principal scheme of the system of vibroacoustic monitoring of wire electrical discharge machining: (a) is a guide, (b) is accelerometers, (c) is a wire-tool, (d) is a workpiece, $(\mathbf{e})$ is a working table, (f) is a fastening system, (g) is preamplifiers, (h) is amplifiers model VShV003 (OOO Izmeritel, Taganrog, Russia), (i) is an ADC E440 (L-card, Saint-Petersburg, Russia), (j) is a signal-recording device.

The pulsed solid-state laser of diode pumping U15 (RMI, Moscow, Russia) was used for laser ablation of AISI 321 samples $(160 \times 100 \times 5 \mathrm{~mm})$ for better understanding the possibilities of in-situ monitoring and adaptive control during pulsed machining processes.

The characterization of electrical discharge impulses was conducted with the use of the digital oscillograph Tektronix TDS2014B (Tektronix Inc., Beaverton, OR, USA).

The characterization of the machined surfaces and the specific wear of the tool was provided by an SEM VEGA 3 LMH (Tescan, Brno, The Czech Republic) and by an optical microscope Olympus BX51M (RYF AG, Grenchen, Switzerland). For the study, the surfaces of workpieces and a wire, and the changes of chemical composition in the sublayer were controlled before and after processing $[10,33]$.

\section{Results}

\subsection{Research A Fundamental Possibility of Vibroacoustic Diagnostics of Wire Electrical Discharge Machining}

\subsubsection{Mathematical Approach and Evaluation of Wire Amplitude Under Discharge Impulses}

The scientists of MSTU Stankin under the supervision of Prof M.P. Kozochkin developed the in-situ monitoring system based on vibroacoustic emission $[44,45]$ and adopted it for the needs of electrical discharge machining (Figures 1 and 2). The preliminary study showed that the oscillations of the wire in the slot during processing might be a reason of instability and turn into the self-oscillation process, which results in the defects of the machined surfaces [46-48].

A diagram of applied forces on the wire during electrical discharge machining presented in Figure 3.

If not taken into attention to the mass of the wire sections $h_{1}$ and $h_{2}$ and mass losses on electroerosion wear $[49,50]$, an amplitude of oscillation may be presented as a complex amplitude of the harmonic signal [51-53]:

$$
\bar{A}_{n}=\bar{A}_{0} \cdot e^{\bar{\beta} \tau},
$$

where $A_{0}$ is an amplitude in the direction of the wire feed, which is always limited by a discharge gap $\Delta$ and much less than $\Delta, A_{n} \leq A_{0}$ for stable EDM processing; $\bar{\beta}$ is the damping coefficient presented as a complex number in the form $(a+b i) ; \tau$ is a period of oscillation $T$. 


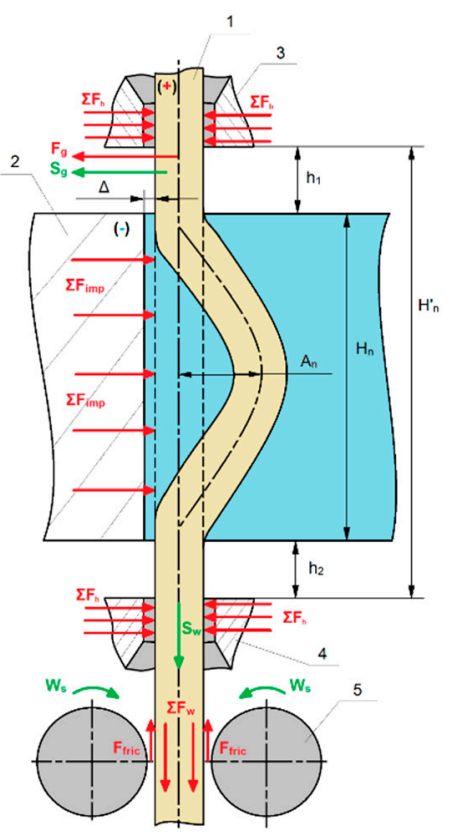

Figure 3. A diagram of applied forces during electrical discharge machining: (1) is a wire tool, (2) is a workpiece, (3) is an upper nozzle, (4) is a lower nozzle, (5) is rollers.

$A_{n}$ is an amplitude of the wire in the inverse direction to the wire feed; $\Delta$ is a discharge gap; $H_{n}$ is a thickness of workpiece; $H_{n}{ }^{\prime}$ is a distance between nozzles; $F_{g}$ is total forces of wire guiding; $\Sigma F_{i m p}$ is total forces of discharge impulses; $\Sigma F_{h}$ is total forces of wire holding; $\Sigma F_{w}$ is total forces of wire tension; $F_{\text {fric }}$ is a friction forces; $S_{g}$ is a wire feed speed; $S_{w}$ is a wire rewinding speed; $W_{s}$ is a torsional moment of rewinding rollers.

$$
\bar{\beta}=\bar{q}-\bar{\mu},
$$

where $\bar{q}$ is an index of excited oscillations; $\mu$ is a coefficient of dielectric medium resistance. In this case, $\bar{q}$ is

$$
\bar{q}=\sqrt{\frac{\sqrt{\bar{h}}-\bar{k}}{2 \cdot m_{n}}},
$$

where $\bar{h}$ is a ratio between $H_{n}$ and $H_{0}, H_{0}$ is a value of the workpiece thickness for stable electrical discharge machining $80 \div 100 \mathrm{~mm}$ for the diameter of wire $d_{w}=0.25 \mathrm{~mm}$ and dielectric based on deionized water; $m_{n}$ is a wire mass; $\bar{k}$ is a ratio between $K_{n}$ and $K_{0}, K_{n}$ is an index of stiffness and can be presented as:

$$
K_{n}=\Sigma F_{\text {imp }} / A_{n}
$$

Thus, $\bar{\beta}$ depends on the ratio of workpiece thickness and the ratio of the system stiffness, the EDM parameters and the viscosity of the working medium; it can vary in the limits $|1|$.

$\bar{q}$ is a criterion of self-oscillation:

$$
\bar{q}=\frac{\lambda}{T}
$$

where $\lambda$ is the logarithmic decrement of the damping ratio of the self-oscillatory and resonant process, describing the decrease in the amplitude of the oscillation process and equal to the natural logarithm of the ratio of two successive amplitudes of the oscillating quantity $A_{n}$ to the same side:

$$
\lambda=\ln \left(A_{n} / A_{n+1}\right),
$$


The period of self-oscillations $T$ depends on the wire mass and the system stiffness, which depends as well on the wire tension:

$$
T=2 \pi \sqrt{\frac{m_{n}}{K_{n}}}
$$

If $q<\mu$, then self- and resonant oscillations do not arise. If $q>\mu$, then the self-oscillations are formed more intense and higher as q excess over $\mu$. $\mu$ is higher for the oil medium and lower for the water-based dielectric. Thus, electrical discharge machining in the oil medium gives a priori higher accuracy of the machined surface.

Simplified calculations based on the measurement of the frequency of forced impulses in the working area gives a possibility to evaluate the wire amplitude during the processing with varied wire tension (Table 3).

Table 3. Results of simplified mathematics for evaluation of wire amplitude under discharge impulses.

\begin{tabular}{cc}
\hline Parameter & Value \\
Wire Mass & \\
A wire radius $r_{w}, \mathrm{~m}$ & 0.00125 \\
A height of the workpiece $H_{n}, \mathrm{~m}$ & 0.016 \\
A distance between the nozzles $H_{n}{ }^{\prime}, \mathrm{m}$ & 0.020 \\
Brass density $\zeta^{1}, \mathrm{~kg} / \mathrm{m}^{3}$ & 8580 \\
A volume of the wire $Q_{w}, \mathrm{~m}^{3}$ & $9.8 \times 10^{-8}$ \\
Wire mass $m_{n}, \mathrm{~kg}$ & $8.4 \times 10^{-4}$ \\
Force of Medium Resistance & 997 \\
Water density $\zeta^{1}, \mathrm{~kg} / \mathrm{m}^{3}$ & $7.8 \times 10^{-5}$ \\
Resistance area $P_{n}\left(=\pi \cdot r_{w} \cdot H_{n}{ }^{\prime}\right)^{1}, \mathrm{~m}^{2}$ & $1.7 \times 10^{-5}$ \\
Wire feed speed $S g, \mathrm{~m}^{2} \mathrm{~s}^{2}$ & $2.2 \times 10^{-11}$ \\
A force of medium resistance $F_{\sigma}{ }^{2}, \mathrm{~N}$ & \\
Force of Impulses & $4.8 \times 10^{-3}$
\end{tabular}

An Amplitude of Wire under Forced Impulses

A frequency of forced impulses $f_{\text {frc }}{ }^{4}, \mathrm{~Hz} \quad 0.2 \times 10^{6}$

System stiffness $K_{w}, \mathrm{~N} / \mathrm{m} \quad 1.1 \times 10^{6}$

An amplitude of wire under forced impulses $A_{f r c}, \mathrm{~m} \quad 4.36 \times 10^{-9}$

${ }^{1}$ Given for reference; ${ }^{2}$ Further ignored due to its small value; ${ }^{3}$ Taken as an approximate value for evaluation of the amplitude for the first pass of electrical discharge machining of the same height workpiece; ${ }^{4}$ Measured in absolute values during experiments.

\subsubsection{Experiments on the Fundamental Possibility of Vibroacoustic Diagnostics}

During the first stage of the experiments, it was established that miserable changes in the weight of the part influence on the vibroacoustic signal. As an example, a $24.5 \mathrm{~g}$-weight of $10 \mathrm{~mm}$-length AISI 321 sample shows a significant increase of the vibroacoustic signal amplitude at $5 \mathrm{~s}$ before the end of processing. For a $4.28 \mathrm{~g}$-weight of $10 \mathrm{~mm}$-length AISI 2024 sample, it was recorded at $2 \mathrm{~s}$ before the end of processing. It was noticed in the full frequency range of the signal. As well, it was characterized by instability in the low frequencies of the signal. Thus, it was chosen to use the frequency range higher than $4 \mathrm{kHz}$ for vibroacoustic monitoring and analyzing.

Figure 4 presents a high-frequency spectrum of vibroacoustic signals recorded at 60 and $5 \mathrm{~s}$ before the part separation. The octave spectra are shown in the inset of the graph. The effective amplitude in the octave-frequency band is more stable than high-frequency spectra of the vibroacoustic signals due to averaging. The effective amplitude with approaching of the end of processing (the moment of separation of the part) increases approximately in 2 times for the octave-frequency band $4 \mathrm{kHz}$ and in 1.5 times for the octave-frequency band $8 \mathrm{kHz}$. So as it can be seen, the occurred moment can be evaluated timely and distantly. The changes can be presented by visual demonstration, which may be understandable for any EDM operator. 


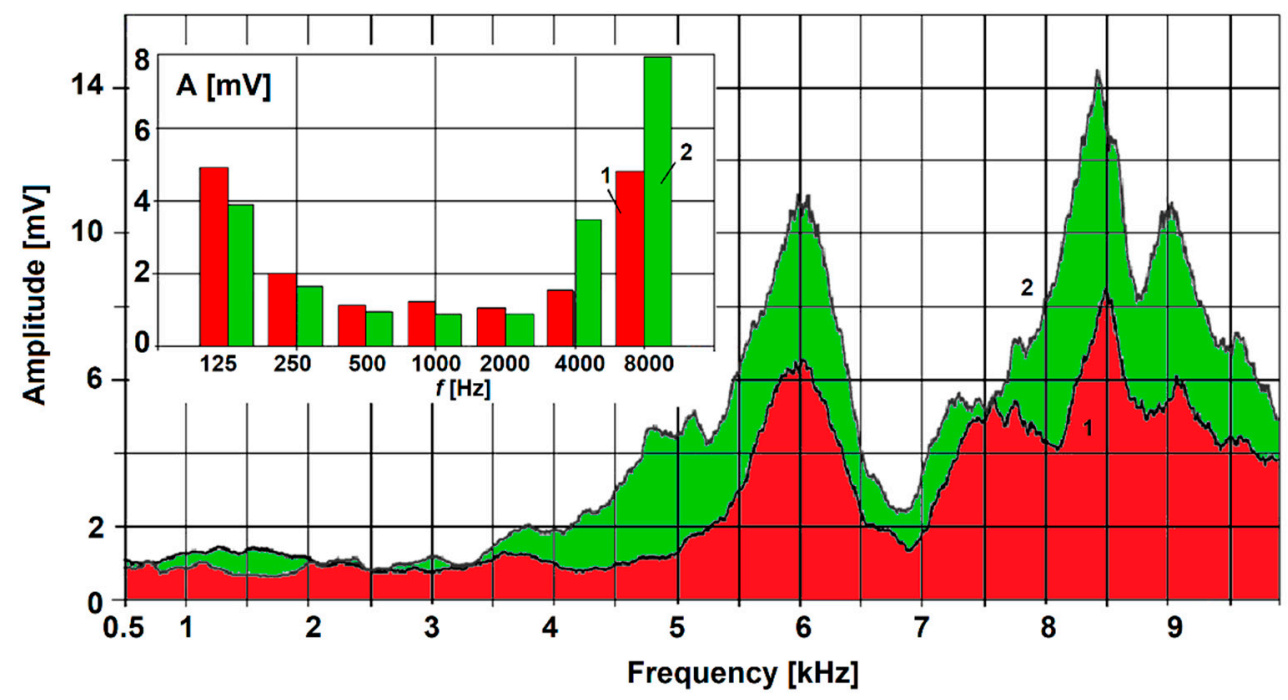

Figure 4. High-frequency spectra of a vibroacoustic signal for electrical discharge machining of AISI 321: (1) is for electrical discharge machining at $60 \mathrm{~s}$ before the end of the operation; (2) is for electrical discharge machining at $5 \mathrm{~s}$ before the end; the inset shows the octave spectra.

Figure 5 presents two spectra of vibroacoustic signals, which were obtained during the electrical discharge machining of the AISI 2024 sample. Spectrum (1) shows the moment of wire penetration, and spectrum (2) shows the moment when the discharge gap is already formed. The changes in root-mean-square value (RMS) of the vibroacoustic signal at the duration of the moment of wire penetration into the workpiece are shown on the inset of the graph.

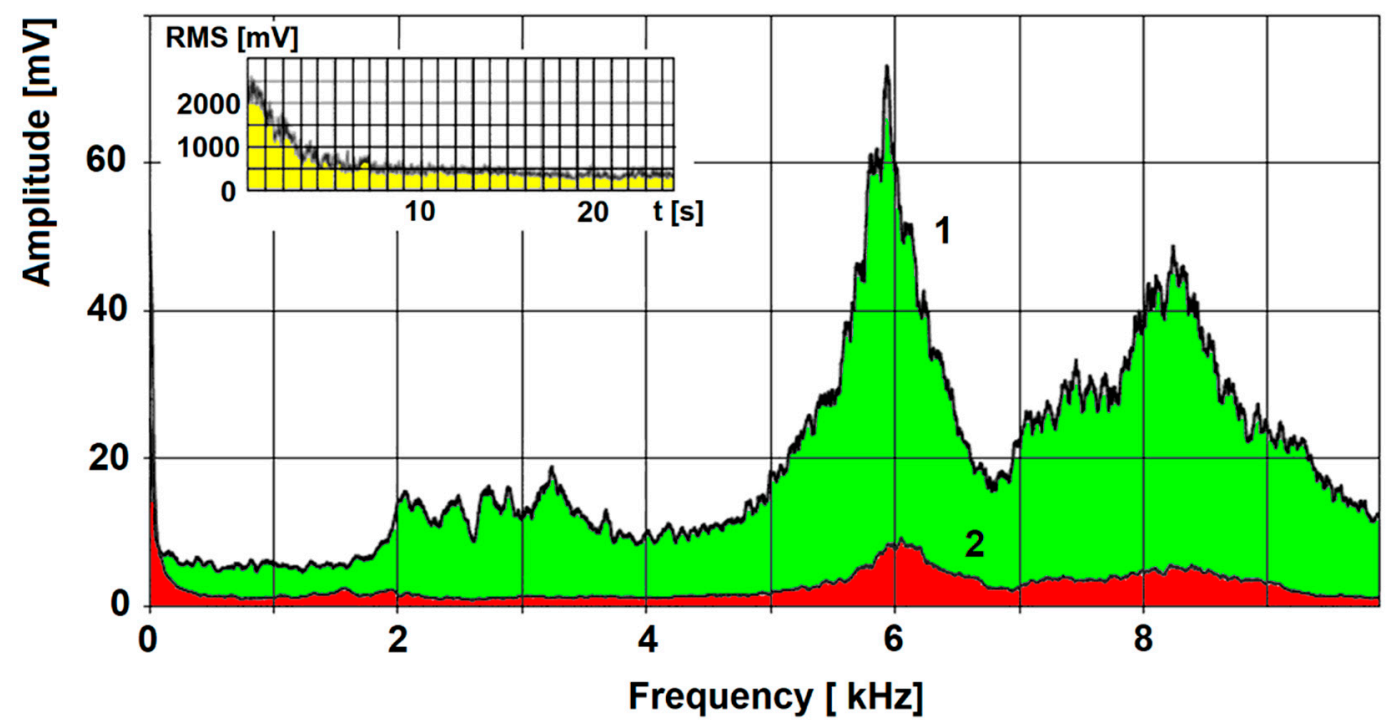

Figure 5. High-frequency spectra of vibroacoustic signals for AISI 2024: (1) is at the moment of wire penetration; (2) at the moment of the discharge gap formation; RMS-t diagram inset presents the spectra of the signal at the moment of wire penetration.

The experimental research of the influence of the wire tool tension $F_{w}$ on vibroacoustic signal showed that decrease of the hardness of elements of the technological system $[1,56,57]$ influences negatively on the growth of the vibration. The growth of vibration was detected with the decline tension force. The detected vibrations were also associated with a decrease of flushing ability of the erosion products from the working zone, which influent negatively on the quality of the machined surfaces. 


\subsection{Adaption of the In-Situ Monitoring Method for the Needs of Electrical Discharge Machining}

The optimization of any machining technology means to ensure its maximum productivity, efficiency, and quality of the machined surfaces up to the required level. It demands the in-time regulation of EDM parameters as the discharge gap $\Delta$, the concentration of erosion product in the gap, the temperature of the working fluid, and its flushing rate. The gap $\Delta$ is the primary parameter, which is responsible for determining the quality of the final product [58-60] A small increase in $\Delta$ may change the conditions in the working area and interrupt the discharge. A decrease in $\Delta$ impairs the yield of erosion products, reduces the productivity, increase accumulation of slag, and provoke short circuits. Electrical discharge machining cannot be effective without automatic regulation of the gap [61,62]. For regulation of the optimal value of the gap, the rate of particle formation $M_{p}$ in the discharge gap should be equal to the rate of particles leaving the gap $M_{e x}$. The rate $M_{p}$ is a function of the concentration of the particles $\gamma$ :

$$
M_{p}=f(\gamma)
$$

When $M_{p}$ and $M_{e x}$ are unequal, the change in concentration of particles is

$$
\Delta \gamma=\Delta M \cdot \Delta t / Q
$$

where $Q$ is the volume of the discharge gap, and

$$
\Delta M=M_{p}-M_{e x}
$$

For stable electrical discharge machining $\Delta \gamma=0$.

However, it is complicated to ensure constant $\gamma$ due to the many factors acting in the working area. Any fluctuations should be timely eliminated by control signals, which change the parameters of electrical discharge machining. The analysis indicates that the maximum rate $M_{p}$ decrease as $M_{e x}$ decreases. It occurs due to the deterioration of the erosion products' evacuation as wire penetrates in the workpiece, and the number of working pulses reduces [58].

Figure 6 presents the dependences of the machining rate $M_{p}$, the number of pulses $\mathrm{n}$ on the discharge gap $\Delta$, where $n_{w}$ is for working pulses, $n_{i d}$ is for idling pulses, $n_{s c}$ is for short-circuit pulses. Analysis indicates that the gap corresponding to the maximum rate $M_{\max }$ is higher than the gap corresponding to the maximum rate of working pulses as an excess of erosion products at the maximum rate of working pulses and short-circuiting pulses destabilize processing [61].

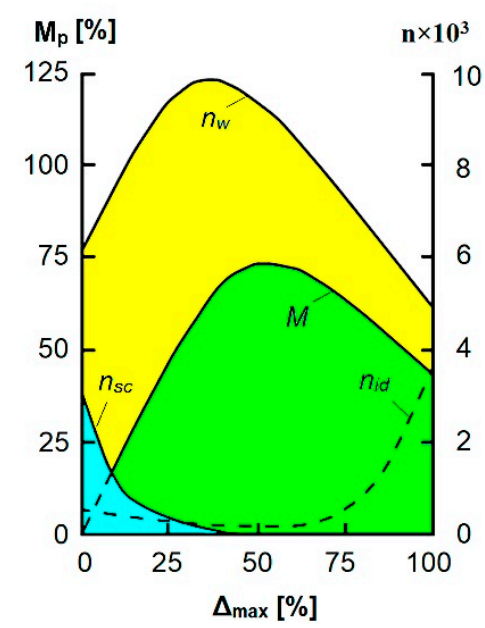

Figure 6. Dependence of the rate $M_{p}$ and the number of pulses $n$ on the discharge gap $\Delta$. 
Thus, the in-situ monitoring systems for electrical discharge machining aim to maintain the efficiency of pulse utilization, which is the ratio of the number of working pulses $\left(n_{w}\right)$ to the total number $n$ of pulses:

$$
\psi=\frac{n_{w}}{n}=0.7 \div 0.9
$$

The rate $\psi$ can be informative for in-situ monitoring and adaptive control, but its use is complicated by the inertia of the required measurement instruments.

Hence, there are difficulties in assessing the efficiency of electrical discharge machining concerning $\psi[33,44]$. The energy of the individual pulses is not entirely consumed in the processing of material sublimation when the dielectric medium is contaminated with erosion product. In this case, a part of the energy is consumed in the destruction of the erosion products. Since the number of working pulses is assessed from the total number of the discharge impulses, it results in an imprecise assessment of the electrical discharge machining efficiency. The precise estimate can be obtained by relating the efficiency to the ratio of the useful energy consumption for sublimation of the material and the total incoming energy of the working impulses in the discharge gap. Normally, the energy of the discharge impulses is proportional to the effective discharge current $\left(I_{e}\right)$ of independent generators in operation. The use of a current sensor can estimate this factor.

\subsection{Analysis of the Obtained Data, Search for the Criteria for the Development of the Adaptive Control System Based on Vibroacoustic Emission}

The results of vibroacoustic monitoring of another non-contact precise machining were considered for better-understanding impulse character of electrical discharge machining and possibility to improve its productivity. Laser ablation is close by its nature to the processes of material removal during electrical discharge machining as in both of the cases there are no mechanical contacts, the material removal occurs under thermal influences, initiated by pulses of concentrated energy fluxes. The material removal during electrical discharge machining is related to the complex processes of chaotic material sublimation under discharge impulses [63] as after laser ablation the surface presents the organized wells [64]. The nature of the initial processes is different.

As it was previously determined [61], the vibroacoustic signals coming in the time of processing demonstrate steady increase as the laser power increases and the volume of removed metal increases (Figure 7).

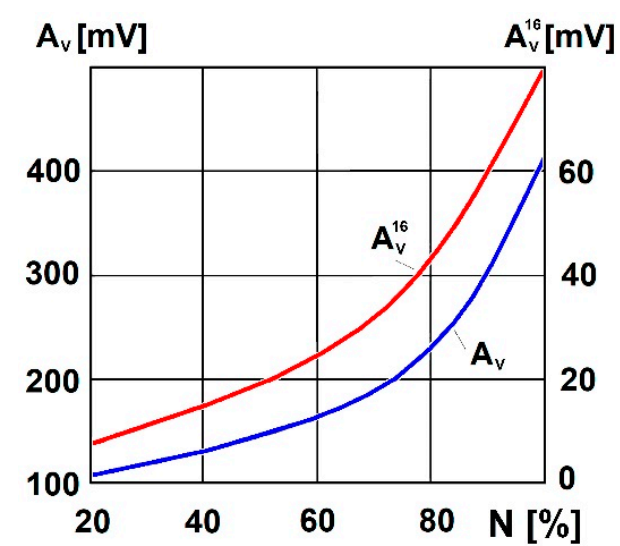

(a)

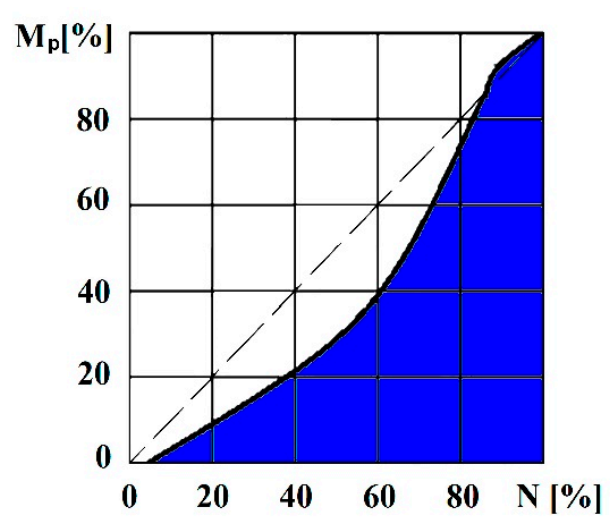

(b)

Figure 7. Dependencies of the effective amplitude of the vibroacoustic signal (a) and productivity (b) from laser power $N$ : $A_{v}$ is a vibroacoustic signal amplitude in wide frequency range; $A_{v}{ }^{16}$ is an amplitudes of the signal of $16 \mathrm{kHz}$ octave.

The presented in Figure $7 \mathrm{~b}$ dependence has a monotonous character. It does not demonstrate any significant material removal at low values of laser power, that is related to lack of thermal energy for 
initiation of material ablation. It can be approximated with linear dependence or exponential function with specified accuracy for the industrial needs.

Figure 7a shows the correlation between vibroacoustic signal amplitude $A_{v a}$ and productivity of the pulses $M_{p}$ after data processing. It can be approximated by an empirical function:

$$
A_{v a}=\zeta \cdot M_{p}^{\Lambda}
$$

where $\Lambda=0.72 \div 0.76, \zeta=$ const.

It is highly possible that the vibroacoustic signal of electrical discharge machining has the same dependences on processing parameters and instead of (8) is easier to use:

$$
A_{v a}=f(\Delta, \gamma)
$$

There is a proved possibility of realization of the in-situ monitoring and adaptive control measures based on vibroacoustic emission for the needs of electrical discharge machining. The parameter of vibroacoustic signals can be observed without any difficulties in the distinction of current pulses productivity.

The dynamic system of electrical discharge machining is linear with dynamic characteristics depending on the state of the dielectric medium. The amplitude spectrum of $U(f)$ signal received by the accelerometer is defined according to the dynamic system linear properties $[44,61]$

$$
U(f)=B_{1}(f) \cdot B_{2}(f) \cdot \Theta(f),
$$

where $B_{1}(f)$ is the frequency response function (FRF) of the operational environment with changes of accumulation of the erosion products, the distance between electrodes, the temperature in the discharge gap (the temperature in the discharge channel is about $7000 \mathrm{~K}$, the temperature of dielectric medium is about $293 \mathrm{~K}) ; B_{2}(f)$ is FRF of a dynamic influence of the discharge impulses on the elastic system; $\Theta(f)$ is an amplitude spectrum, $f$ is the frequency.

The energy of vibroacoustic signals changes in the dependence on the concentrated energy flux intensity on the machining surface. A part of energy flow is spent on repeated sublimation of erosion products in the discharge gap. As a result, it crates chaotic and overlapped wells on machined, it chanes as well the conditions in the discharge gap. The formed overlaps cause localization of the following discharge. Thus, the impulses created by phase transfer of the processed metal are longer in time.

Therefore, the concentration of erosion products' $\gamma$ increase as short impulses decrease and long impulses increase. The transformations result in changes of dynamic characteristic $B_{1}(f)$ including changes in FRF of $B(f)$ :

$$
B(f)=B_{1}(f) \cdot B_{2}(f)
$$

The current values $B(f)$ during electrical discharge machining can be evaluated by controlling discharging current and vibroacoustic signal. The experiment showed that $B_{2}(f)$ might be presented as constant in the short period of observation. Thus, the changes in $B(f)$ are related to the changes in dielectric medium conditions $B_{1}(f)$.

\subsection{Demonstration of the Opportunity for The In-situ Adaptive Control of Edm by Specific Examples}

The developed in-situ monitoring technique was approbated on the high-precision wire electrical discharge machine CUT1000 (GF AgieCharmilles SA, Losone, Switzerland) during processing of the samples made of hard alloys, which can be actual for the modern machine building industry: M05 and P10, ISO. The vibroacoustic signals and discharge current were recorded during experiments. FRF of $B(f)$ in the observation channel was fixed at the moment of wire approach to a workpiece and the moment wire break. Figure 8 presents an FRF of $B(f)$ in the channel of observation. The vibroacoustic signals were recorded in [mV], FRF values were non-dimensional. 


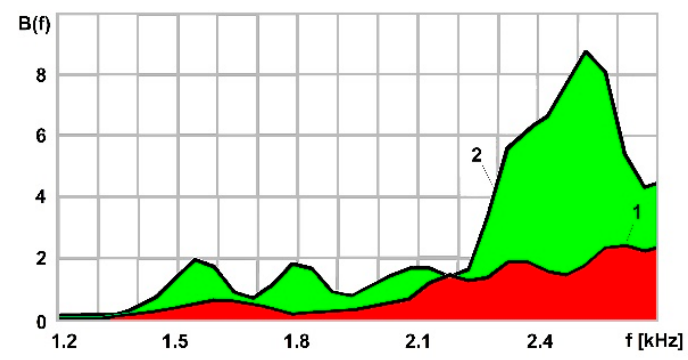

(a)

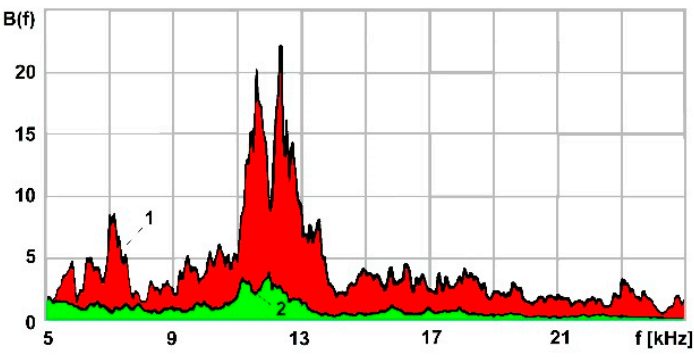

(b)

Figure 8. The record of FRF during electrical discharge machining of M05 hard alloy: (a) is in the low-frequency range; (b) is in the high-frequency range; (1) is at the moment of wire approach; (2) is before the wire break.

During the period of the initial stage of wire approach (1), the dielectric is clean of erosion products, the wire approaches to the flat surface of the workpiece, the erosion products easily flush from the discharge gap. The highest value of amplitude fixed at the frequency range $11 \div 13 \mathrm{kHz}$.

The wire break occurs at $12 \mathrm{~s}$ of electrical discharge machining (2). There were observed a decrease in high-frequency components and an increase in low-frequency components at the frequency range $2.4 \div 2.6 \mathrm{kHz}$. The flushing of erosion products was straitened before the wire break. The short impulses decreased, and long impulses increased for forming of the groove.

It was noticed that FRF changes in the full frequency range are not convenient due to possible disturbance from the work of the equipment. One or two frequency ranges where FRF changes can be easily monitored should be chosen for the development of the adaptive control method.

Figure 9 presents an example of RMS vibroacoustic signal change in various octave bands: from the wire approach to breaking.

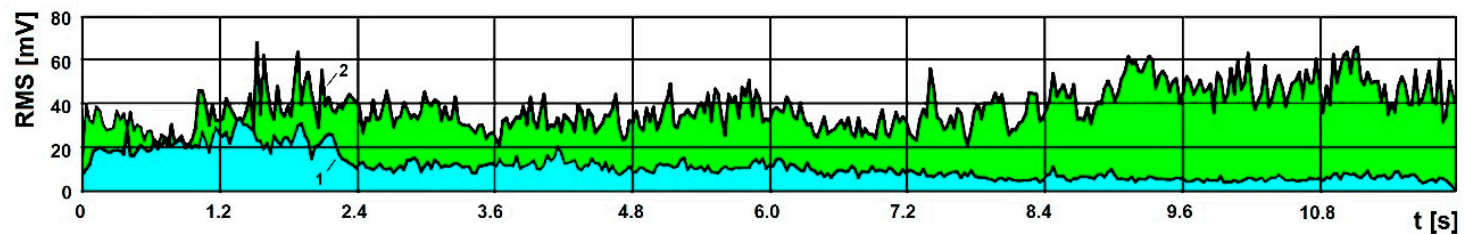

(a)

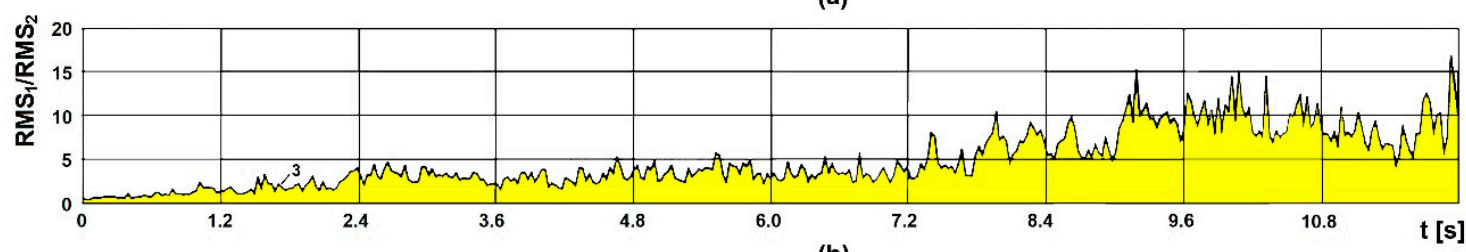

(b)

Figure 9. RMS of vibroacoustic signals during $12 \mathrm{~s}$ of electrical discharge machining of M05 hard alloy: (a) RMS of vibroacoustic signal; (b) proportional ratio of RMS1/RMS2, where (1) is an octave band of $2 \mathrm{kHz}$; (2) is an octave band of $32 \mathrm{kHz}$; (3) is the result of interconnection.

The power of discharging current has not any significant changes during changes of RMS of the vibroacoustic signal; hence, the components of the vibroacoustic signal demonstrates the tendency of changes in the conditions of the discharge gap. A gradual increase in RMS of low-frequency vibroacoustic signal (1) and a significant decrease in the RMS of the high-frequency signal (2) was recorded during machining. Graph 3 shows the change in the ratio of RMS of a low-frequency signal to RMS of a high-frequency signal. The ratio gives a more informative picture of a decrease in the conditions of electrical discharge machining. The stable phase of processing was observed until $7 \mathrm{~s}$ and then an increase in 10 times of RMS of a vibroacoustic signal from $3 \div 4 \mathrm{~s}$ was observed; it achieves briefly 15 -fold value. 
As the control system of the machine reacted only to indirect electrical parameters, in particular, to a coefficient of impulse use, the critical increase of the concentration of the erosion products was left without proper attention. It resulted in overheating of electrodes and consequent wire break.

The exceptional use of data in the electric format of impulses control system results in consideration of the impulses directed to the sublimation of the erosion products in the discharge gap as effective. At the same time, the vibroacoustic signals from such impulses cannot be created and detected at all, or they have a narrow range of frequency spectra.

Figure 10 shows the examples of vibroacoustic signal impulses of various shapes at various spark gaps. It can be seen the discharges current impulses in the form of vibroacoustic signals of less than $0.1 \mathrm{~ms}$ in length (a). The length of separate vibroacoustic signals' fragments at the high concentration of erosion products increases up to 5-6 times (b). The long fragments (impulses) provide an increase of low-frequency elements of the spectra of a vibroacoustic signal.

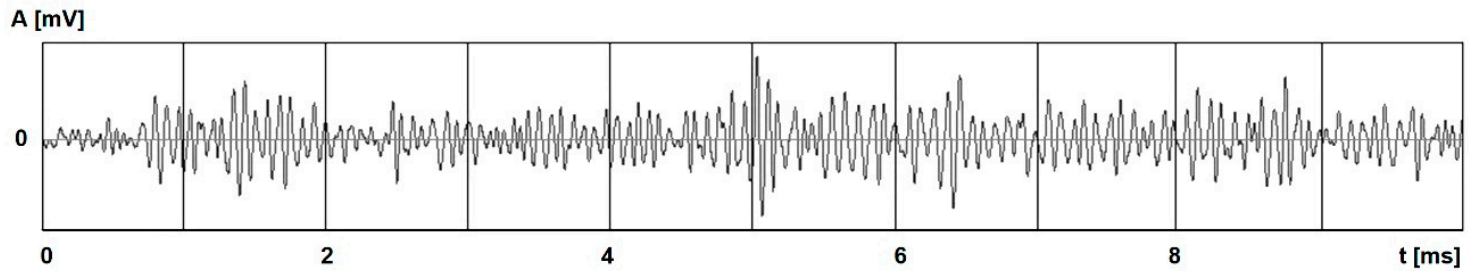

(a)

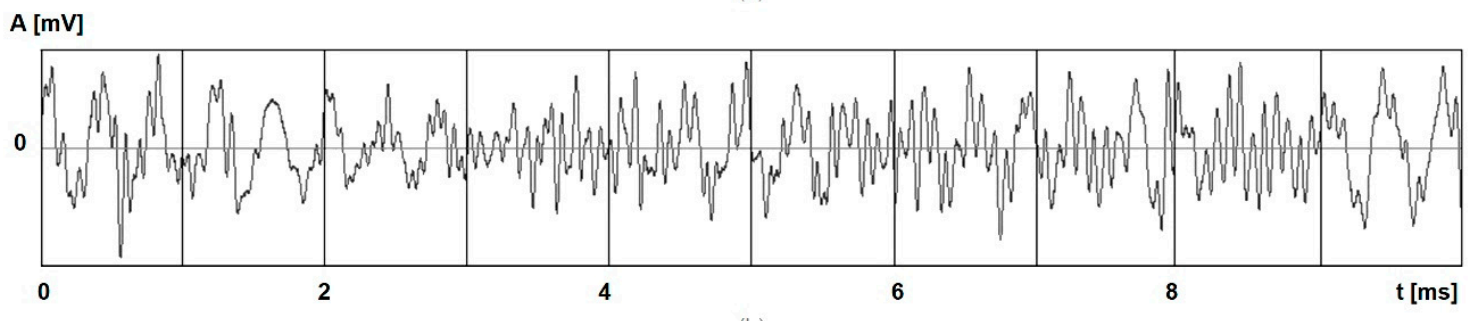

(b)

Figure 10. Vibroacoustic signals at $10 \mathrm{~ms}$ period during electrical discharge machining of M05 hard alloy: (a) is at the moment of wire approach; $(\mathbf{b})$ is before wire break.

\section{Discussion}

In the begging, it was decided to focus attention at the moment of separation of the part from the workpiece, which gives changes in the specific noise accompanied electrical discharge machining. By this vibroacoustic emission, it is possible to recognize a specific noise related to each stage of plastic deformation and brittle fracture of the part separation.

It was shown that an amplitude of the vibroacoustic signal increases gradually with the approach of the moment of the separation (Figure 4). Then the series of peaks of the diagram related to the possible wire stuck in the discharge gap and consequent short-circuiting. It proves the final bridge is weakening due to rapid mass loss under electroerosion pulses. Then the part starts rotated motion relatively lower contact point between a part and a workpiece when the upper part of the bridge is separated. The wire tool stays clasped between a separated part and the rest of the workpiece. The series of the short circuits occur, and the vertical traces of the wire can be observed on the samples of the material with the electrical resistance more than $7.9 \times 10^{-8} \Omega \cdot \mathrm{m}$.

During the experiments, it was noticed that the intensity of vibroacoustic signals increases as the symmetry of the wire tool position in the gap is disturbed. It is related to the prevalence of the discharge current pulses acting on one of the sides of the wire tool. This kind of phenomena was also detected at the moment of wire tool penetration into a workpiece when there is no stable discharge gap between the electrodes. At the moment when the discharge gap is established, and a wire tool penetrated the workpiece and formed a discharge groove, the acting pulses balance each other and the amplitude of the vibroacoustic signal decreases. 
It can be detected from the obtained vibroacoustic diagram (Figure 5) of the spectra that at the $5 \div 7 \mathrm{~s}$ the RMS value of the spectra increases four times in frequency range of $8 \mathrm{kHz}$. It is noticeable even for alloys of transition metals with the relatively low-melting-point (more than $231.9^{\circ} \mathrm{C}$ and less than $\left.950^{\circ} \mathrm{C}\right)$ and low electrical resistance $\left(2.8 \times 10^{-8} \Omega \cdot \mathrm{m}\right)$. The described changes of the vibroacoustic signal are thoroughly enough for developing in-situ monitoring and adaptive control system for taking measures timely to prevent short-circuiting and consequent defects of the machined surfaces.

The absolute excess of the vibroacoustic amplitude during conventional machining after penetration of the tool in the workpiece can be explained by an excess of the erosion products (solidified particles of the eroded material) in the discharge gap. The excess of the erosion products usually related to the insufficient flushing in the working zone due to the relatively high height of the workpiece (more than $70 \div 100 \mathrm{~mm}$ for the wire tool $0.25 \mathrm{~mm}$ ) or relatively low pressure of dielectric in the nozzles (code " 1 " instead of " 2 " for the first tool pass, rough cutting). It may also be related to the relatively small discharge gap (less than $0.005 \mathrm{~mm}$ ) for the materials with the high electrical resistance (more than $1.12 \times 10^{-6} \Omega \cdot \mathrm{m}$ ) due to the difficulties in controlling it by the servo drives of the machine tool.

Thus, it may be possible that:

(1) For the lower value of wire tension, the adequate flushing of the erosion products is hampered by bending of a wire tool during processing and higher wire amplitude due to the low circular frequency of the vibrations, when the circular frequency of the forced oscillations under electrical impulses is above the circular frequency of the self-oscillation;

(2) For the higher value of wire tension, the flushing of the erosion products is adequate, but the stiffness of the system is higher, then wire amplitude is lower, at the same time, the circular frequency of the vibrations grows, when the circular frequency of the forced oscillations under electrical impulses is below the circular frequency of the self-oscillation;

(3) For the value of wire tension associated with stable EDM processing, the circular frequency of forced oscillation may be compensated by the frequency of self-oscillation.

Therefore, it was shown that the non-contact electrical discharge machining generates the vibroacoustic signal in the full frequency range that is quite similar by its character to the character of vibroacoustic emission during the convenient mechanical machining. It was proved that the signal might be registered by accelerometers placed on the elastic system of the machine tool wirelessly and at a distance from a working zone to exclude the influence on accuracy positioning of drivers and the parameters of machining. It was determined that the vibroacoustic signal is a result of wire tool disturbance in the discharge gap by discharge current pulses, cavitation processes and intensity of flushing in the working medium, wire tool contacts with the workpiece or erosion products.

The positions of the accelerometers were chosen based on the idea that the accelerometers should be placed as close as possible to the working zone. However, the installation of the lower accelerometer on the lower guide was inconvenient as it is moving under a workpiece and the wires of the accelerometers can hamper the processing. Therefore, it was more suitable to place it closer on the fastening system of the workpiece for monitoring of workpiece vibration. The upper accelerometer was placed on the upper guide for monitoring of wire vibration, and it was most informative and convenient for development of the adaptive control system.

It was found during the study, the upper accelerometer records the vibrations which are associated with the total forces of the working discharge impulses, which are directed in the destruction of the workpiece $\left(\Sigma F_{\text {imp.w }}\right)$, but not in the destruction of the erosion products in the discharge gap $\left(\Sigma F_{\text {imp.idle }}\right)$. In this case, the total forces of initiated impulses, which can be detected by monitoring only electrical parameters, is:

$$
\sum F_{i m p}=\sum F_{i m p . w}+\sum F_{i m p . i d l e}
$$

It should be noted that not all working impulses carry out the same and useful work. Some of them spent a part of the energy or even all its energy on the destruction of the erosion products [65-67]. 
The experiments showed that the performance of the EDM (volume in $\mathrm{mm}^{3}$ ) is related to the power of the vibroacoustic signal by a linear dependence (or close to linear) (Figure 7). Besides, it follows that the control of the share of working pulses at high frequencies is associated with great difficulties in the field of circuit engineering and with large errors as it is known from published sources [55,58,59]. It is the advantage of the vibroacoustic signal over the method of controlling the pulse utilization rate $(\psi)$.

In other words, during discharge gap breakdown all initiated pulses are considered to be working pulses by measuring electrical parameters, which is not correct because a part of the pulses is spent on the destruction of the erosion products in the discharge gap. It is suitable for the cases when there is a low part of the erosion products in the discharge gap. In the case of vibroacoustic monitoring, only the pulses directed on the destruction of another electrode are taken into account as working impulses.

Moreover, the measurement of the vibroacoustic signal in [mV] is suitable as the amplitude of the vibroacoustic signal is proportional to the signal in $[\mathrm{mV}]$ at the output of the measuring channel. In principle, the measurements in $[\mathrm{mV}]$ can be converted to the measurement of vibration acceleration $\left[\mathrm{m} / \mathrm{s}^{2}\right]$, but it is unnecessary work called "calibration." For the adaptive control system development, it is enough to have measurement units, which are proportional to amplitude.

The widespread use of vibroacoustic spectra for diagnostics and monitoring is complicated as it is a closed system with a nonlinear dependence of the vibroacoustic signal on the impulse load [68,69]. The dynamic system resembles better a linear model, where the dynamic relation between the load source and the workpiece is permanent.

In other words, the model of the dynamic system is significantly simplified, and its use in the in-situ monitoring and regulation of machining by high-energy fluxes is simplified [70,71].

\section{Conclusions}

The application of the developed in-situ monitoring technique using vibroacoustic spectra of the signal in the working zone can provide a current solution for the specific issues related to the insufficient productivity of electrical discharge machining and low quality of the machined surfaces due to technological issues of processing (e.g., wire breakage).

The developed method is based on the effect of the vibroacoustic emission during processing. Physical phenomena of vibroacoustic emission explained the fundamental possibility of this method. It was shown the interconnections between the electrical parameters of machining and vibroacoustic spectra, and the possibility to timely analyze the received vibroacoustic spectra data for development of the system of the adaptive control.

For further development, it is necessary to conduct more intensive research with the high electrical resistant materials to show the principle possibilities to adapt the electrical parameters of the processing for the needs of processing of new classes materials as nanocomposites based on ceramics and made with the use of carbon tubes and whiskers. It was shown that the developed method is suitable for operative positioning of wire tool-electrode or evaluation of wire tool-electrode bending during processing. That can be extremely important for the production of the parts with a complex linear configuration for the needs of the aircraft industry.

The study of processing of workpieces with high energy impulses shows that their effectiveness and parameters of vibroacoustic signals depend on the power of impulses supplied with monotonous analogic dependencies. It allows monitoring of the current effectiveness of flushing in the working zone and optimizes the value of the discharge gap.

The unstable electrical discharge processing is also associated with multiple contacts of electrodes and short-circuiting during processing that cannot be identified timely by modern CNC-system, but this problem can be solved with the adequate data received by monitoring system based on vibroacoustic emission. Analysis of vibroacoustic signals can provide a modern solution for resolving the manufacturing issues, which is not covered by existing methods of electrical parameters control and helps in forming a multi-parameter and multifunctional diagnostic system. 


\section{Patents}

1. Kozochkin, M.P.; Grigoriev, S.N.; Porvatov, A.N., Okunkova, A.A. The method of controlling the electrical discharge machining of parts on an automated cutting machine with a system of $\mathrm{CNC}$; RU 2598022

2. Kozochkin, M.P.; Khoteenkov, K.E.; Porvatov, A.N., Grigoriev, S.N. The method of EDM cutting of products; RU 2638607

3. Grigoriev, S.N.; Kozochkin, M.P.; Okunkova, A.A. The method of positioning the wire electrode on the EDM cutting machines; RU 2572678

Author Contributions: Conceptualization: A.A.O. and M.P.K.; methodology: M.P.K. and A.N.P.; software, A.N.P.; validation: M.P.K., A.N.P., and Y.A.M.; formal analysis: M.P.K.; investigation: A.N.P.; resources: Y.A.M.; data curation: A.A.O.; writing-original draft preparation: M.P.K. and A.N.P.; writing—review and editing: M.P.K. and A.A.O.; visualization: A.A.O. and A.N.P.; supervision: Y.A.M.; project administration: Y.A.M. and M.P.K.; funding acquisition: A.A.O. and Y.A.M.

Funding: This research was funded by the Ministry of Education and Science of Russian Federation, grant number No. 9.7453.2017/6.7.

Acknowledgments: The research was done at the Laboratories of the Department of High-efficiency Machining Technologies of MSTU Stankin.

Conflicts of Interest: The authors declare no conflict of interest.

\section{References}

1. Conde, A.; Arriandiaga, A.; Sanchez, J.A.; Portillo, E.; Plaza, S.; Cabanes, I. High-accuracy wire electrical discharge machining using artificial neural networks and optimization techniques. Robot. Cim-Int. Manuf. 2018, 49, 24-38. [CrossRef]

2. Maradia, U.; Filisetti, E.; Boccadoro, M.; Rotenb, M.; Dutoit, J.-M.; Hengsberger, S. Increasing the Injection Moulding Productivity through EDM Surface Modulation. Proc. CIRP 2018, 68, 58-63. [CrossRef]

3. Sahu, A.K.; Chatterjee, S.; Nayak, P.K.; Mahapatra, S.S. Study on effect of tool electrodes on surface finish during electrical discharge machining of Nitinol. IOP Conf. Ser. Mater. Sci. Eng. 2018, 338, 012033. [CrossRef]

4. Trung, K.H. Development of a WEDM system with high machining efficiency. In Proceedings of the 2017 International Conference on System Science and Engineering (ICSSE), Ho Chi Minh City, Vietnam, 21-23 July 2017; pp. 397-399. [CrossRef]

5. Ho, K.H.; Newman, S.T.; Rahimifard, S.; Allen, R.D. State of the Art in Wire Electrical Discharge Machining (WEDM). Int. J. Mach. Tool Manuf. 2004, 44, 1247-1259. [CrossRef]

6. Han, F.; Chen, L.; Yu, D.; Zhou, X. Basic study on pulse generator for micro-EDM. Int. J. Adv. Manuf. Technol. 2007, 33, 474-479. [CrossRef]

7. Faisal, N.; Kumar, K. Optimization of Machine Process Parameters in EDM for EN 31 Using Evolutionary Optimization Techniques. Technologies 2018, 6, 54. [CrossRef]

8. Gavrin, V.N.; Kozlova, Y.P.; Veretenkin, E.P.; Logachev, A.V.; Logacheva, A.I.; Lednev, I.S.; Okunkova, A.A. Reactor target from metal chromium for "pure" high-intensive artificial neutrino source. Phys. Part. Nucl. Lett. 2016, 13, 267-273. [CrossRef]

9. Prathipati, R.P.; Devuri, V.; Cheepu, M.; Gudimetla, K.; Kiran, R.U. Machining of AISI D2 Tool Steel with Multiple Hole Electrodes by EDM Process. IOP Conf. Ser. Mater. Sci. Eng. 2018, 330, 012067. [CrossRef]

10. Volosova, M.A.; Okunkova, A.A.; Povolotskiy, D.E.; Podrabinnik, P.A. Study of electrical discharge machining for the parts of nuclear industry usage. Mech. Ind. 2015, 16, 706. [CrossRef]

11. Ozerkan, H.B. Simultaneous machining and surface alloying of AISI 1040 steel by electrical discharge machining with boron oxide powders. J. Mech. Sci. Technol. 2018, 32, 4357-4364. [CrossRef]

12. Bhattacharya, S.; Abraham, G.J.; Mishra, A.; Kain, V.; Dey, G.K. Corrosion Behavior of Wire Electrical Discharge Machined Surfaces of P91 Steel. J. Mater. Eng. Perform. 2018, 27, 4561-4570. [CrossRef]

13. Nguyen, H.P.; Pham, V.D.; Ngo, N.V. Application of TOPSIS to Taguchi method for multi-characteristic optimization of electrical discharge machining with titanium powder mixed into dielectric fluid. Int. J. Adv. Manuf. Technol. 2018, 98, 1179. [CrossRef] 
14. Uhlmann, E.; Oberschmidt, D.; Bolz, R. Application of Micro Structured, Boron Doped CVD-diamond as $\mu$ EDM Tool Electrodes. Proc. CIRP 2018, 68, 649-653. [CrossRef]

15. Jayalakshmi, S.; Singh, R.A.; Gupta, M. Metallic Glasses as Potential Reinforcements in Al and Mg Matrices: A Review. Technologies 2018, 6, 40. [CrossRef]

16. Veronesi, P.; Leonelli, C.; Bondioli, F. Energy Efficiency in the Microwave-Assisted Solid-State Synthesis of Cobalt Aluminate Pigment. Technologies 2017, 5, 42. [CrossRef]

17. Fleischer, J.; Teti, R.; Lanza, G.; Mativenga, P.; Möhring, H.C.; Caggiano, A. Composite materials parts manufacturing. CIRP Ann. 2018, 67, 603-626. [CrossRef]

18. Nakamura, M.; Takeo, K.; Osada, T.; Ozaki, S. Finite Element Analysis of Self-Healing and Damage Processes in Alumina/SiC Composite Ceramics. Technologies 2017, 5, 40. [CrossRef]

19. Aimable, A.; Doubi, H.G.; Stuer, M.; Stuer, M.; Zhao, Z.; Bowen, P. Synthesis and Sintering of ZnO Nanopowders. Technologies 2017, 5, 28. [CrossRef]

20. Song, C.; Cheng, L.; Liu, Y.; Zhao, M.; Ye, F. Microstructure and electromagnetic wave absorption properties of RGO-SiBCN composites via PDC technology. Ceram. Int. 2018, 44, 18759-18769. [CrossRef]

21. Zhang, C.; Shi, Z.; Mao, F.; Yang, C.; Yang, J.; Zhu, X.; Zuo, H. Polymer composites with balanced dielectric constant and loss via constructing trilayer architecture. J. Mater. Sci. 2018, 53, 13230. [CrossRef]

22. Yan, Z.; Sun, H.; Chen, X.; Fu, X.; Chen, C.; Cheng, F.; Chen, J. Rapid low-temperature synthesis of perovskite/carbon nanocomposites as superior electrocatalysts for oxygen reduction in Zn-air batteries. Nano Res. 2018, 11, 3282. [CrossRef]

23. Mishra, M.K.; Moharana, S.; Mahaling, R.N. Fabrication of SiC-Treated P(VDF-HFP)-(BFO-SO3H) Composite Films for High Performance Energy Storage Device (HPESD) Applications. Phys. Status Solidi A 2018, 215, 1701057. [CrossRef]

24. Jang, J.-S.; Lee, G.Z.; Kim, H.; Hong, S.Y.; Ci, L.; Nam, J.D.; Suhr, J. High-damping and conducting epoxy nanocomposite using both zinc oxide particles and carbon nanofibers. J. Mater. 2018, 4, 187-193. [CrossRef]

25. Sato, K.; Tominaga, Y.; Hotta, Y.; Shibuya, H.; Sugie, M.; Saruyama, T. Cellulose nanofiber/nanodiamond composite films: Thermal conductivity enhancement achieved by a tuned nanostructure. Adv. Powder Technol. 2018, 29, 972-976. [CrossRef]

26. Grigoriev, S.N.; Volosova, M.A.; Gurin, V.D.; Seleznev, A.E. Wear of replaceable indexable inserts made of mixed cutting ceramics CC650 as a function of force parameters of steel ShKh15 face milling. J. Frict. Wear 2015, 36, 521-527. [CrossRef]

27. Grigoriev, S.N.; Gurin, V.D.; Volosova, M.A.; Cherkasova, N.Y. Development of residual cutting tool life prediction algorithm by processing on CNC machine tool. Materialwiss. Werkst. 2013, 44, 790-796. [CrossRef]

28. Grigoriev, S.N.; Sinopalnikov, V.A.; Tereshin, M.V.; Gurin, V.D. Control of parameters of the cutting process on the basis of diagnostics of the machine tool and workpiece. Meas. Tech. 2012, 55, 555-558. [CrossRef]

29. Volosova, M.; Grigoriev, S.; Metel, A.; Shein, A. The Role of Thin-Film Vacuum-Plasma Coatings and Their Influence on the Efficiency of Ceramic Cutting Inserts. Coatings 2018, 8, 287. [CrossRef]

30. Grigoriev, S.N.; Volosova, M.A.; Gurin, V.D.; Seleznyov, A.Y. Investigation of force parameters acting on a single cutting insert made of ceramics in face milling of hardened steel. Mech. Ind. 2015, 16, 702. [CrossRef]

31. He, Y.; Chen, X.; Liu, Z.; Qin, Y. Piezoelectric self-sensing actuator for active vibration control of motorized spindle based on adaptive signal separation. Smart Mater. Struct. 2018, 27, 065011. [CrossRef]

32. Schneider, F.; Mummert, K. Chemical aspects of stress corrosion cracking of AISI 321 stainless steel in hot aqueous chloride solutions. ChemInform 1997, 28. [CrossRef]

33. Grigoriev, S.N.; Kozochkin, M.P.; Kropotkina, E.Y.; Okunkova, A.A. Study of wire tool-electrode behavior during electrical discharge machining by vibroacoustic monitoring. Mech. Ind. 2016, 17, 717. [CrossRef]

34. Kustas, F.; Molian, P.; Kumar, A.S.; Besser, M.; Sordelet, D. Laser crystallization of amorphous sputter-deposited quasicrystalline coatings. Surf. Coat. Technol. 2004, 188, 274-280. [CrossRef]

35. Gautam, A.; Ajit, K.P.; Sarkar, P.K. A nonlinear CDM based damage growth law for ductile materials. Mater. Res. Express 2018, 5, 026518. [CrossRef]

36. Weidner, A.; Lippmann, T.; Biermann, H. Crack initiation in the very high cycle fatigue regime of nitrided 42CrMo4 steel. J. Mater. Res. 2017, 32, 4305-4316. [CrossRef]

37. Takada, N.; Hayashi, Y.; Goto, M.; Sasaki, K. An Attempt to Produce Electrical Discharges in Acoustic Cavitation Bubbles. Plasma Fusion Res. 2016, 11, 1406113. [CrossRef] 
38. Yu, X.; Qiu, M.; Fu, J.; Kong, L.; Han, Y. Multi-channel aerosol dielectric electrical discharge machining ablation based on discrete electrode. Int. J. Adv. Manuf. Technol. 2018, 99, 1037-1045. [CrossRef]

39. Pinahin, I.A.; Chernigovskij, V.A.; Bracihin, A.A.; Yagmurov, M.A. Improvement of wear resistance of VK6, VK8, T5K10, and T15K6 hard alloys by volume pulsed laser hardening. J. Frict. Wear 2015, 36, 330-333. [CrossRef]

40. Blinkov, I.V.; Belov, D.S.; Volkhonskii, A.O.; Blinkov, V.I.; Shatalov, R.L. Structure of Nanocrystalline Arc-PVD (Ti, Al)N Coatings Modified with Nickel. Russ. Metall. 2015, 5, 421-427. [CrossRef]

41. Sheleg, V.K.; Shaturov, D.G.; Shaturov, G.F. Analysis and Selection of Rational Cutting Modes while Using Hard-Alloy Tool for Shaft Turning. Sci. Tech. 2018, 17, 14-20. [CrossRef]

42. Sokolov, A.G.; Bobylyov, E.E. The element-phase composition and properties of the surface layers of carbide-tipped tools made of TK and WC-Co alloys. Lett. Mater. 2017, 7, 222-228. [CrossRef]

43. Lin, Y.-C.; Hung, J.-C.; Lee, H.-M.; Wang, A.C.; Chen, J.T. Machining characteristics of a hybrid process of EDM in gas combined with ultrasonic vibration. Int. J. Adv. Manuf. Technol. 2017, 92, 2801-2808. [CrossRef]

44. Kozochkin, M.P.; Porvatov, A.N.; Grigor'ev, S.N. Vibroacoustic Monitoring of the Major Parameters of Electrical Discharge Machining. Meas. Tech. 2017, 59, 1228-1233. [CrossRef]

45. Zhang, Z.; Liu, M.; Liao, Y.; Su, Z.; Xiao, Y. Contact acoustic nonlinearity (CAN)-based continuous monitoring of bolt loosening: Hybrid use of high-order harmonics and spectral sidebands. Mech. Syst. Signal. Proc. 2018, 103, 280-294. [CrossRef]

46. Liang, J.F.; Liao, Y.S.; Kao, J.Y.; Huang, C.H.; Hsu, C.Y. Study of the EDM performance to produce a stable process and surface modification. Int. J. Adv. Manuf. Technol. 2018, 95, 1743-1750. [CrossRef]

47. Jain, P.S.; Ravindra, H.V.; Ugrasen, G.; Prakash, G.N.; Rammohan, Y.S. Study of Surface Roughness and AE Signals while Machining Titanium Grade-2 Material using ANN in WEDM. Mater. Today Proc. 2017, 4, 9557-9560. [CrossRef]

48. Grigoriev, S.N.; Kozochkin, M.P.; Porvatov, A.N.; Pinargote, S.; Washington, N. Features of Vibro-Acoustic Monitoring EDM of Conductive Ceramics. Mater. Sci. Forum 2016, 876, 8-13. [CrossRef]

49. Corný, I.; Pitel, J.; Hašová, S. Statistical Approach to Optimize the Process Parameters of HAZ of Tool Steel EN X32CrMoV12-28 after Die-Sinking EDM with SF-Cu Electrode. Metals 2017, 7, 35. [CrossRef]

50. Salinas, C.F.P.; Moya, E.; Coello, D. Use of an orthogonal arrangement for the analysis of the process of die sink electrical discharge machining with shape electrodes of graphite and copper on aluminum micro-casting. Enfoque UTE 2018, 9, 67-79.

51. Liu, Y.; Chang, H.; Zhang, W.; Ma, F.; Sha, Z.; Zhang, S. A Simulation Study of Debris Removal Process in Ultrasonic Vibration Assisted Electrical Discharge Machining (EDM) of Deep Holes. Micromachines 2018, 9 , 378. [CrossRef]

52. Xiao, X.; Zheng, X.; Wang, Y.; Xu, S.; Zheng, Z. A Method for Utility Harmonic Impedance Estimation Based on Constrained Complex Independent Component Analysis. Energies 2018, 11, 2247. [CrossRef]

53. Herrojo, C.; Moras, M.; Paredes, F.; Núñez, A.; Ramon, E.; Mata-Contreras, J.; Martín, F. Very Low-Cost 80-Bit Chipless-RFID Tags Inkjet Printed on Ordinary Paper. Technologies 2018, 6, 52. [CrossRef]

54. Tamura, T.; Kobayashi, Y. Measurement of impulsive forces and crater formation in impulse discharge. J. Mater. Process. Technol. 2004, 149, 212-216. [CrossRef]

55. Mohri, N.; Yamada, H.; Furutani, K.; Narikiyo, T.; Magara, T. System identification of wire electrical discharge machining. CIRP Ann. 1998, 47, 173-176. [CrossRef]

56. Pang, L.; Hosseini, A.; Hussein, H.M.; Deiab, I.; Kishawy, H.A. Application of a new thick zone model to the cutting mechanics during end-milling. Int. J. Mech. Sci. 2015, 96, 91-100. [CrossRef]

57. Kozochkin, M.P.; Porvatov, A.N.; Sabirov, F.S. Vibration Testing of Technological Processes in Automated Machining Equipment. Meas. Tech. 2014, 56, 1414-1420. [CrossRef]

58. Artamonov, B.A.; Volkov, Y.S. Analiz Modelei Elektrokhimicheskoi I Elektroerozionnoi Obrabotki. Chast' 2, Modeli Protsessov Elektroerozionnoi Obrabotki. Provolochnaya Vyrezka (Analysis of Models of Electrochemical and Electrodischarge Treatment, Part 2: Models of Electrodischarge Treatment. Wire Cutting), 1st ed.; Vseross. Nauchno-issled. Inst. Patent. Inform.: Moscow, Russia, 1991; pp. 98-101. (In Russian)

59. Gutkin, B.G. Avtomatizatsiya Elektroerozionnykh Stankov (Automation of Electrical Discharge Machines); Mashinostroenie: Leningrad, USSR, 1971; pp. 28-29. (In Russian)

60. Maity, K.; Mishra, H. ANN modelling and Elitist teaching learning approach for multi-objective optimization of mu-EDM. J. Intell. Manuf. 2018, 29, 1599-1616. [CrossRef] 
61. Grigor'ev, S.N.; Kozochkin, M.P. Improvement of Machining by the Vibroacoustic Diagnostics of Electrophysical Processes. Rus. Eng. Res. 2015, 35, 801-806. [CrossRef]

62. Fu, X.; Zhang, Q.; Gao, L.; Liu, Q.; Wang, K.; Zhang, Y.W. A novel micro-EDM-piezoelectric self-adaptive micro-EDM. Int. J. Adv. Manuf. Technol. 2016, 85, 817-824. [CrossRef]

63. Yue, X.; Yang, X.; Tian, J.; He, Z.; Fan, Y. Thermal, mechanical and chemical material removal mechanism of carbon fiber reinforced polymers in electrical discharge machining. Int. J. Mach. Tools Manuf. 2018, 133, 4-17. [CrossRef]

64. Abdelmalek, A.; Bedrane, Z.; Amara, E.-H.; Sotillo, B.; Bharadwaj, V.; Ramponi, R.; Eaton, S. Ablation of Copper Metal Films by Femtosecond Laser Multipulse Irradiation. Appl. Sci. 2018, 8, 1826. [CrossRef]

65. Isaev, A.; Grechishnikov, V.; Pivkin, P.; Mihail, K.; Yuriy, I.; Andrey, V. Machining of thin-walled parts produced by additive manufacturing technologies. Proc. CIRP 2016, 41, 1023-1026. [CrossRef]

66. Kozochkin, M.P.; Porvatov, A.N. Effect of adhesion bonds in friction contact on vibroacoustic signal and autooscillations. J. Frict. Wear 2014, 35, 389-395. [CrossRef]

67. Kozochkin, M.P.; Sabirov, F.S. Attractors in cutting and their future use in diagnostics. Meas. Tech. 2009, 52, 166-171. [CrossRef]

68. Schmitz, T.L.; Smith, K.S. Machining Dynamics. Frequency Response to Improved Productivity; Springer: New York, NY, USA, 2009; pp. 108-109. ISBN 978-0-387-09645-2.

69. Altintas, Y. Manufacturing Automation: Metal Cutting Mechanics, Machine Tool Vibrations, and CNC Design, 2nd ed.; Cambridge University Press: Cambridge, UK, 2012; pp. 68-70. ISBN 978-0-511-84372-3.

70. Webster, J.; Dong, W.P.; Lindsay, R. Raw Acoustic Emission Signal Analysis of Grinding Process. CIRP Ann. 1996, 45, 335-340. [CrossRef]

71. Grabec, L.; Leskovar, P. Acoustic emission of a cutting process. Ultrasonic 1977, 15, 17-20. [CrossRef]

(C) 2018 by the authors. Licensee MDPI, Basel, Switzerland. This article is an open access article distributed under the terms and conditions of the Creative Commons Attribution (CC BY) license (http:/ / creativecommons.org/licenses/by/4.0/). 